NOTICIAS DE LA FACULTAD

\section{Tallerescuela 50 + 50. Cincuenta años de arquitectura en Lo Contador}

Para celebrar los cincuenta años de la Escuela de Arquitectura en el campus Lo Contador de la PUc, el Centro de Estudiantes en conjunto con la Dirección de la Escuela llevaron a cabo la actividad Tallerescuela $50+50$ Cincuenta años de arquitectura en Lo Contador, entre los días 13 y 16 de octubre de 2009. Como eje central se desarrolló un concurso que planteaba la creación de un futuro escenario para el campus en el contexto de la Universidad, el barrio Pedro de Valdivia Norte y la ciudad de Santiago. Su objetivo principal era generar una instancia a nivel de escuela, en la cual interactuaran alumnos de todos los niveles, participando 18 equipos en total. El jurado estuvo compuesto por Juan Ignacio Baixas -Director Escuela de Arquitectura-, Pilar García -Subdirectora Escuela de Arquitectura-, Mario Ubilla -Director Escuela de Diseño-, Montserrat Palmer -Directora Ediciones ARQ-,los profesores Pilar Urrejola, Alex
Moreno, Teodoro Fernández y Pablo Saric y el Presidente del Centro de Estudiantes de Arquitectura Felipe Vera.

El equipo ganador estuvo compuesto por los alumnos de Taller de Ejercitación: Cristián Hurtado, Cristóbal Mingo, Santiago Melo, Diego Sepúlveda, Luis Vacaflores, Andrea Reyes, Diego Teran y Cristián Lavín; los alumnos de Taller V: Florencia Rodríguez, Tomás Wainstein, Gonzalo Molina y Melisa Miranda; los alumnos de Taller IV: Teresita Giesen, María Luisa Arze, Javiera Loaiza y Constanza Valdivieso; los alumnos de Taller II: Trinidad Antunovic, Nicolás Lira, Catalina Kutscher y Pablo del Río y por Isidira Bauerle - sin taller-. El equipo estuvo a cargo de los profesores Carolina Katz y Martín Andrade.

La premiación se realizó durante la fiesta de gala llevada a cabo el día 16 de octubre, como clausura de la semana Tallerescuela.

\section{Fe de erratas}

En el número 72 de la revista ARQ se omitieron algunos datos correspondientes a las filiaciones institucionales de la autora del artículo "Países Bajos, territorio reversible", que se detallan a continuación:

Dice:

Países Bajos, territorio reversible Carolina Contreras Profesora, Pontificia Universidad Católica de Chile

Carolina Contreras Professor, Pontificia Universidad Católica de Chile

Debe decir:

Países Bajos, territorio reversible

Carolina Contreras Profesora, Pontificia Universidad Católica de Chile y Universidad Diego Portales Carolina Contreras Lecturer, Pontificia Universidad Católica de Chile y Universidad Diego Portales 